\title{
The effect of a retrieval cue on the return of spider fear
}

Citation for published version (APA):

Dibbets, P., Moor, C., \& Voncken, M. J. (2013). The effect of a retrieval cue on the return of spider fear. Journal of Behavior Therapy and Experimental Psychiatry, 44(4), 361-367.

https://doi.org/10.1016/j.jbtep.2013.03.005

Document status and date:

Published: 01/12/2013

DOI:

10.1016/j.jbtep.2013.03.005

Document Version:

Publisher's PDF, also known as Version of record

Document license:

Taverne

\section{Please check the document version of this publication:}

- A submitted manuscript is the version of the article upon submission and before peer-review. There can be important differences between the submitted version and the official published version of record.

People interested in the research are advised to contact the author for the final version of the publication, or visit the DOI to the publisher's website.

- The final author version and the galley proof are versions of the publication after peer review.

- The final published version features the final layout of the paper including the volume, issue and page numbers.

Link to publication

\footnotetext{
General rights Owners
rights.

- You may freely distribute the URL identifying the publication in the public portal. please follow below link for the End User Agreement:

www.umlib.nl/taverne-license

Take down policy

If you believe that this document breaches copyright please contact us at:

repository@maastrichtuniversity.nl

providing details and we will investigate your claim.
}

Copyright and moral rights for the publications made accessible in the public portal are retained by the authors and/or other copyright owners and it is a condition of accessing publications that users recognise and abide by the legal requirements associated with these

- Users may download and print one copy of any publication from the public portal for the purpose of private study or research.

- You may not further distribute the material or use it for any profit-making activity or commercial gain

If the publication is distributed under the terms of Article $25 \mathrm{fa}$ of the Dutch Copyright Act, indicated by the "Taverne" license above, 


\title{
The effect of a retrieval cue on the return of spider fear
}

\author{
Pauline Dibbets*, Charlotte Moor, Marisol J. Voncken \\ Faculty of Psychology and Neuroscience, Maastricht University, The Netherlands
}

\section{A R T I C L E I N F O}

\section{Article history:}

Received 8 June 2012

Received in revised form

20 December 2012

Accepted 27 March 2013

\section{Keywords:}

Spider fear

Exposure

Retrieval cue

Renewal

Context dependency

\begin{abstract}
A B S T R A C T
Background and objectives: Exposure therapy is often used as treatment for anxiety disorders. However, a change in context after exposure can result in fear renewal. This renewal can be attenuated by using retrieval cues stemming from the exposure context. The present study investigated the effect of such a cue in spider-fearful persons.

Methods: Thirty-three participants underwent an in vivo exposure session while wearing a bracelet (retrieval cue). After exposure, half of the participants continued to wear the bracelet at home until follow-up (cue groups); the other half handed over the bracelet after exposure (no cue groups). Half of the participants in each group received the follow-up in the exposure context (AAcue and AAnocue); for the other half follow-up was conducted in a novel environment (ABcue and ABnocue).

Results: A switch in context at follow-up resulted in more self-reported anxiety and arousal compared to no switch. However, the retrieval cue did not attenuate this renewed responding.

Limitations: The number of participant per condition was limited, which might have obscured possible retrieval cue effects due to a lack of power. Additionally, information about the retrieval cue was provided after exposure, which might have weakened the association between the cue and exposure therapy. Furthermore, no autonomic measures were incorporated, restricting the effect to self-report measures. For future studies we would recommend to explicitly link the retrieval cue before onset of the exposure session and to incorporate autonomic measures.

Conclusions: Our findings indicate that a switch in context resulted in more self-reported anxiety and arousal, but that a cue stemming from the exposure context did not attenuate this renewal.
\end{abstract}

(c) 2013 Elsevier Ltd. All rights reserved.

\section{Introduction}

Exposure therapy is a common treatment of many anxiety disorders such as specific phobias (Öst, 1997), obsessive-compulsive disorder (Abramowitz, 1996; Marks, Hodgson, \& Rachman, 1975), post-traumatic stress disorder (Foa, Rothbaum, \& Furr, 2003), or panic disorder (Barlow, Allen, \& Basden, 2007) and involves repeated and systematic exposure to the feared object or situation. Such in vivo exposure therapy is usually conducted in a graduated fashion, starting from the least anxiety-provoking aspect to the most anxiety-provoking aspect of the feared stimulus or situation (Öst, 1997). In addition, the therapist often models each step, provides information, and shows how to interact with the phobic stimulus situation.

Although most of the above-mentioned anxiety problems respond robustly to this type of treatment, return of fear is

\footnotetext{
* Corresponding author. Maastricht University, Clinical Psychological Science, P.O. Box 616, 6200 MD Maastricht, The Netherlands. Tel.: +31 (0) 4338815 97; fax: +31 (0) 433884155 .

E-mail address: Pauline.Dibbets@maastrichtuniversity.nl (P. Dibbets).
}

frequently observed (e.g., Choy, Fyer, \& Lipsitz, 2007; Mystkowski, Craske, \& Echiverri, 2002; Rodriguez, Craske, Mineka, \& Hladek, 1999). According to Bouton $(2002,2004)$ this return of fear is evidence that exposure (or extinction) does not destroy the original learning, but instead new learning takes place. This new learning is more or less confined to the environment or timeframe in which the exposure or extinction session took place (e.g., Bouton, 2002, 2004). Just the mere passage of time or encountering the feared object outside the 'safe' exposure context can trigger the old fear memory and elicit a renewed fear response.

These contextual renewal effects are not restricted to experimental settings with induced fear responses (e.g., Neumann \& Kitlertsirivatana, 2010; Neumann \& Longbottom, 2008), but can also be observed in (sub)clinical settings such as the return of spider fear (Mineka, Mystkowski, Hladek, \& Rodriguez, 1999; Mystkowski et al., 2002; Mystkowski, Mineka, Vernon, \& Zinbarg, 2003; Rodriguez et al., 1999). For example, a spider-fearful person is repeatedly exposed to a spider in a therapeutic setting. As a result new learning occurs and the fear response extinguishes. However, encountering a spider outside this context, for example at home, can trigger the old fear memory and lead to a renewed fear response. 
Several ways have been put forward to reduce a renewal effect after an extinction procedure or exposure therapy (see for reviews Bouton, 2002; Havermans \& Jansen, 2003). A feasible and promising option that stems from animal studies is the incorporation of extinction retrieval cues (Brooks \& Bouton, 1993, 1994). Retrieval cues are distinctive stimuli that are present during the extinction or exposure phase. Outside the extinction context these cues can function as a reminder of the extinction phase and facilitate retrieval of the, often less accessible, extinction memory.

The last decade, the use of retrieval cues in humans has gained attention. Several fear conditioning experiments have been conducted that tested the influence of a retrieval cue using computerized tasks (e.g., Dibbets, Havermans, \& Arntz, 2008; Dibbets \& Maes, 2011; Vansteenwegen et al., 2006). In these studies a change in context after extinction resulted in renewed responding. In the studies of Dibbets et al. (2008) and Dibbets \& Maes (2011), the amount of renewal was attenuated when a retrieval cue stemming from the extinction context was co-present indicating that, at least partially, the extinction memory was retrieved.

Abovementioned studies indicate that a retrieval cue can attenuate fear renewal in a healthy population. However, to our knowledge only one study has tested the clinical relevance of retrieval cues using in vivo fear exposure (Culver, Stoyanova, \& Craske, 2011). In this study students that were highly fearful of public speaking received an exposure session. The retrieval cues comprised of a white lab coat, a pen, and clipboard; the contexts used were two different rooms. The results indicated that a change in context after exposure resulted in fear renewal (Study 1). However, the authors were unable to find strong effects of the cues in retrieving extinction learning outside the exposure context. Only weak attenuation of renewal was observed; this effect was restricted to a dichotomous analysis of self-report data (Study 2). A replication with larger contextual differences did not reveal any effect of retrieval cues on renewal (Study 3). A possible explanation of the absence of a strong retrieval cue effect is that the cues were not explicitly encoded as part of the exposure context. As a result, the cues could not facilitate the retrieval of the extinction/exposure memory (Culver et al., 2011). Second, the cue was not presented between the exposure and the renewal test (one week later). Presenting the cue between exposure and follow-up has two advantages. First, it might prevent renewal between the exposure and follow-up session in case the feared stimulus or situation is encountered. Second, the retrieval cue can lead to the mental rehearsal of the exposure session. This latter is important as mental reinstatement of the exposure session and context might reduce the return of fear (e.g., Mystkowski, Craske, Echiverri, \& Labus, 2006).

In sum, a change in context after extinction or exposure can elicit renewed responding in healthy as well as fearful participants. Evidence is available that a retrieval cue is an effective way to attenuate this renewal in healthy persons. Some, although weak, evidence exists that such a cue might be effective in fearful participants (Culver et al., 2011). The present study aims at extending previous results by testing the efficacy of a retrieval cue in spiderfearful persons. In order to establish a stronger link between the retrieval cue and exposure memory, the retrieval cues were explicitly linked to the exposure session and available between the exposure session and follow-up test.

Based on previous findings, we expected that a change in context after extinction would result in renewed responding and that this renewal would be attenuated by the presence of a retrieval cue.

The present study is highly important as it not only extends the sparse literature on the clinical relevance of retrieval cues, but is also a next step to assess the possibility to implement such cue in clinical exposure sessions.

\section{Method}

\subsection{Participants}

Thirty-three spider-fearful participants ( 1 male, 32 females) with scores between 16 and 27 on the Spider Phobia Questionnaire (SPQ, Klorman, Weerts, Hastings, Melamed, \& Lang, 1974) were included. All participants reported a "marked and persistent fear that is excessive or unreasonable, cued by the presence or anticipation of a spider" for at least 6 months during a structured clinical diagnostic interview (SCID-I, Van Groenestijn, Akkerhuis, Kupka, Schneider, \& Nolen, 1997).

\subsection{Experimental conditions}

A $2 \times 2$ factorial design was used with context (same versus switch) and retrieval cue (present versus absent) as betweensubject factors resulting in four conditions (see Table 1). Participants were pseudo-randomly assigned to one of the four conditions, with the restriction that the persons that reported the highest and lowest amount of spider fear (SPQ scores and SCID-I interview) were equally distributed. Contextual cues were counterbalanced. Half of the participants received the exposure session and follow-up in the same context $(n=16, \mathrm{AA})$, half of the participants received the treatment and follow-up in different contexts $(n=17, \mathrm{AB})$. Half of the participants received a retrieval cue between the two sessions and at test ( $n=17$, cue), whereas no cue was provided for the other half ( $n=16$, no cue).

\subsection{Stimuli}

Two trained female university employees were used as therapists. The therapists differed regarding age (26 versus 39 years), clothing, posture (voluptuous versus lean), hair color and style (short and blond versus brown and long), and eyes (blue versus brown). Two different rooms on different floors served as contextual stimuli: a lab decorated as a bar (normally part of studies on alcohol cue reactivity) and a standard office room. The labs differed regarding decoration, floor covering, illumination color (yellow versus white light), furniture, and shape. Also the exposure material, except for the spiders, differed (e.g., color and form of the washing basins, brushes, table, etc.).

The retrieval cue was a colored rubber bracelet with a metal fastener. The participant was free to select the preferred color in order to enhance compliance. The bracelets had a distinct citronella odor (see also www.mosquitno.nl) and originally served as mosquito repellents. This citronella odor was easily noticeable and did not decline during the testing period. Using a compound retrieval cue has two advantages. First, two different modalities are activated, increasing the saliency of the retrieval cue and second, in case a part of the compound is unavailable (e.g., clothes covering the bracelet or having a cold) the remainder of the compound can help to retrieve the exposure memory.

Three different spiders served as phobic stimuli: a small giant house spider (Tegenaria gigantea $1 \mathrm{~cm}$ ), a vibrating spider

Table 1

Overview of the experimental design.

\begin{tabular}{|c|c|c|c|c|}
\hline & AAcue & AAnocue & ABcue & ABnocue \\
\hline Session 1 Exposure & A cue & A cue & A cue & A cue \\
\hline $\begin{array}{l}\text { Week between Session } 1 \\
\text { and Session } 2\end{array}$ & Cue & No cue & Cue & No cue \\
\hline Session 2 Follow-up & A cue & A no cue & B cue & B no cue \\
\hline
\end{tabular}

Note: $A$ and $B$ represent different contexts, cue and no cue indicate whether the cue was present or absent, respectively. Contexts were fully counterbalanced. 
(Pholcidae, $1 \mathrm{~cm}$ ), and a small tarantula (Holothele incei, $2.5 \mathrm{~cm}$ ) that strongly resembles a large giant house spider. All exposure sessions started with the small tarantula.

\subsection{Questionnaires and measures}

\subsubsection{Structured Clinical Interview for DSM-IV Axis I (SCID-I)}

A Dutch version of the SCID-I was used to assess spider fear (Van Groenestijn et al., 1997). The inter-rater reliability proves to be adequate (Martin, Pollock, Bukstein, \& Lynch, 2000).

\subsubsection{Spider Phobia Questionnaire (SPQ)}

The SPQ developed by Klorman et al. (1974) is a validated 31item self report instrument to asses fear of spiders. The SPQ score can range from 0 to 31, with higher scores representing more selfreported spider fear. The Dutch version, used for the present study, has an adequate test-retest stability, correlation of .94, and internal consistency, with a Cronbach's alpha of .91 (Muris \& Merckelbach, 1996).

\subsubsection{Spider Beliefs Questionnaire (SBQ)}

The SBQ (Arntz, Lavy, Van den Berg, \& Van Rijsoort, 1993) is a Dutch questionnaire that assesses the strength of irrational/unrealistic beliefs about spiders (1) and the self (2) during confrontation with a spider. Scores can range from 0 to 78 . The SBQ has been shown to have an excellent internal consistency, .94, with a reasonable test-retest reliability of .68 (beliefs about spiders) and .71 (self and spiders) (Arntz et al., 1993).

\subsubsection{Fear of Spiders Questionnaire (FSQ)}

The FSQ (Szymanski \& O'Donohue, 1995) is an 18-item selfreport instrument that measures fear of spiders. Scores range between 18 and 126, with higher scores reflecting higher levels of spider fear. The Dutch version, used for the present study, has an adequate test-retest reliability, correlation of .91, and an internal consistency ranging between .95 and .97 (Muris \& Merckelbach, 1996).

\subsubsection{Retrieval cue}

To disguise the function of the retrieval cue (no cue groups), a cover-up story and mock questionnaire about the bracelet were included. Mosquitno was introduced as a sponsor for the experiment and provider of the bracelets. In return, Mosquitno would like to receive information about the color, odor, and comfort of the bracelet. Additionally, the participant was asked to give a reasonable price for the bracelet and whether he/she would recommend the bracelet to others.

\subsubsection{Behavioral Approach Test (BAT)}

The BAT measures the physical distance (in centimeters) between the participant and the spider. For example, a BAT of 0 indicates that the participant is able to touch the spider; a BAT of 150 indicates a distance of $150 \mathrm{~cm}$ between the spider and the participant.

\subsubsection{Subjective Units of Distress Scales (SUD)}

The SUDs used for the present study comprise three visual analogue scales of $100 \mathrm{~mm}$ each to measure the amount of fear, disgust, and arousal at various points during the study. Outer left (score of 0 ) indicates no fear, no disgust, or no arousal, outer right represents extreme fear, disgust, and arousal (score of 100).

\subsubsection{Steps and time}

In consultation with the participant, an individual gradual exposure schedule was made that was based on the protocol of Öst
(1997). The total number of completed steps in the fear hierarchy (see Table 2) and the duration of each step were recorded.

\subsection{Procedure}

The experiment comprised two sessions, Session 1, in which exposure took place, and a follow-up session, Session 2. Session 1 was divided in a pre-treatment, exposure, and post-treatment phase and was conducted by one of the two therapists. In case of a context change, Session 2 was conducted by the alternative therapist.

\subsubsection{Session 1}

Pre-treatment. At the start of Session 1 the participant was welcomed and guided to the instruction room. The participant received written information about the experimental procedure and then signed an informed consent (approved by local ethical committee, ECP-93). After an adaptation phase of $5 \mathrm{~min}$ the participant received instructions for the pre-treatment BAT (BAT\#1). In the assigned experimental context the participant was asked to rapidly approach the caged small tarantula, open the container, and touch the spider (BAT\#1). At the closest distance to the spider (measured in centimeters) the participant was asked to rate the amount of fear, disgust, and arousal using the SUDs (SUD\#1). Next, the participant completed the SBQ (SBQ\#1) and FSQ (FSQ\#1) in the experimental context and then returned to the instruction room for a 5 min break.

Exposure. The participant returned to the treatment context and received written bogus information about the sponsorship of Mosquitno. Then the participant was asked to select a bracelet and to put it on. If necessary, the bracelet was shortened and reattached with the metal fastener. Subsequently, the experimenter explained the rationale of the exposure treatment and a fear hierarchy, that included at least all steps of Table 2, was constructed in consultation with the participant. Steps were recoded in such way that each of the twelve steps of Table 2 was identical across participants (e.g., step 5 was for all participants Focus on the spider with the container top open).

Each step was first modeled by the experimenter who then guided the participant in performing the step. A step was repeated until SUDs scores were 25 or below, or on request of the participant, at which point the exposure progressed to the next step in the hierarchy. Treatment was stopped when the participant was able to perform the last step in the hierarchy reporting a SUDs rating of 25

Table 2

Exposure hierarchy.

\begin{tabular}{ll}
\hline Step & Description \\
\hline 1 & Stand $152 \mathrm{~cm}$ from the spider in a closed container \\
2 & Stand $30 \mathrm{~cm}$ from the spider and look at it in the closed container \\
3 & Place the palm of one of your hands against the closed container \\
4 & Stand at a close distance to the spider's closed container \\
& and place the palm of your hand on the container, \\
& with your face $30 \mathrm{~cm}$ from the container \\
5 & Focus on the spider with the container top open \\
6 & Watch the spider as it crawls around a washing bin \\
7 & (step 6-14 in washing bin) \\
8 & Direct the spider's movement with a small brush, 5 times \\
9 & Touch the spider with a heavily gloved hand, 5 times \\
10 & Let the spider walk over a heavily gloved hand \\
11 & Touch the spider with a latex-gloved hand, 5 times \\
12 & Let the spider walk over a latex-gloved hand \\
$13^{\mathrm{a}}$ & Touch the spider with bare finger, 5 times \\
$14^{\mathrm{a}}$ & Let the spider walk on bare hand with arm covered \\
\hline
\end{tabular}

${ }^{\text {a }}$ Optional steps, on direction of the participant. 
or lower, or if the participant was unwilling to perform the next step in the hierarchy. The maximum amount of time allotted to the exposure phase was $4.5 \mathrm{~h}$.

Post-treatment. After the exposure treatment, the participant returned to the instruction room for a $5 \mathrm{~min}$ break and then returned to the experimental room. The participant engaged another BAT (BAT\#2), filled out the SUDs (SUD\#2), completed the SBQ (SBQ\#2), FSQ (FSQ\#2), and the questionnaire concerning the bracelet in the experimental room. Participants in the cue groups received additional instructions to wear the bracelet between Session 1 and Session 2 as a reminder of the exposure session. They were instructed to wear the bracelet as often as possible, but allowed to remove the bracelet during sport, taking a shower, and during sleep. Additionally, the bracelet was explicitly linked to the exposure session by referring to the following elements: successfulness of the session, overcome their fear, and pride (e.g., "each time you see this bracelet remind this successful session. Think of how you managed to overcome your fear and re-experience the pride as you touched the spider"). They were instructed that in case of encountering a spider to think of the bracelet and the successful exposure session. The no cue participants did not receive these instructions and handed over the bracelet to the experimenter.

\subsubsection{Session 2}

One week after the treatment the follow-up session took place. The participant was received in the same instruction room as Session 1 . The follow-up was either scheduled in the same experimental room, with the same experimenter, wearing the same clothes (AAcue and AAnocue groups) or in a novel room, with the alternative experimenter (ABcue and ABnocue groups). For all participants the same spider was used as during the exposure session. After entering the experimental room, the participant engaged another BAT (BAT\#3) and filled out the SUDs (SUD\#3). If the participant was not able to touch the spider, he/she was encouraged to perform the last possible step of the personal fear hierarchy. Next, the participant filled out the SBQ (SBQ\#3), FSQ (FSQ\#3), and SPQ (SPQ\#2). Finally, a short interview was conducted. All participants were asked if they had encountered any spiders in the past week, if so, how they reacted. They were asked about the usefulness of the exposure session and if their spider fear had diminished. The cue groups received additional questions concerning the bracelet such as: how much they had worn the bracelet, if it had functioned as a retrieval cue, and whether the bracelet functioned as a reminder during the BAT\#3.

\subsection{Dependent measures and statistical analyses}

The measures included in the data analyses were the total scores on the SPQ, FSQ and SBQ; distance to the spider and accompanying SUDs (fear, disgust, and arousal) on the BAT\#1, BAT\#2, and BAT\#3. Additionally, the amount of completed steps of the exposure hierarchy and total exposure time were analyzed.

Data were parametrically analyzed using (repeated measures) ANOVAs. Context (same versus switch) and cue (present or absent) served as between-subjects factors. Effects sizes were expressed as partial eta squared, $\mathrm{p} \eta^{2}$. In case of violations of sphericity, Greenhouse Geisser corrections were made; Bonferroni corrections were made in case of multiple comparisons. The significance level was set at $p<.05$.

\subsubsection{Analytic strategy}

First, possible pre-existing group differences regarding demographic variables and spider fear were examined. Second, the effectiveness of the exposures session was examined by comparing pre-exposure and post-exposure measures. Third, to assess relapse, follow-up scores were compared to post-exposure scores. Finally, to examine if relapse resulted in complete renewal of the fear response, follow-up scores were compared to pre-exposure scores.

\section{Results}

\subsection{Demographic variables}

Table 3 summarizes the demographic information per experimental condition. The data of all 33 participants were included. No differences between the groups were observed concerning age, $F(3$, $29)=2.08, p=.12, \mathrm{p} \eta^{2}=.18$, or SCID-I scores, $F<1$.

\subsection{Pre-exposure}

Before onset of the exposure no differences were observed regarding the SPQ\#1, FSQ\#1, and SBQ\#1 scores (see Table 4), Fs $<1$. Neither did the groups differ on the initial approach distance to the spider (BAT\#1), $F<1$, or on the reported fear and arousal SUD scores (see Table 5 ), $F \mathrm{~s}<1$. A marginally significant effect of group was observed on the SUD disgust score, $F(3,28)=2.79, p=.059$, $\mathrm{p} \eta^{2}=.23$. Post hoc tests revealed that the AAcue group tended to display less disgust than the remaining three groups, $.11<p s<.17$.

\subsection{Exposure}

The groups did not differ regarding to the number of completed exposure steps, total exposure duration, or approach distance after exposure, BAT\#2, Fs $<1$. No group differences were observed concerning the questionnaires (FSQ\#2 and SBQ\#2) or SUDs, Fs $<1$. For only four participants a different spider than the small tarantula was used during the exposure and follow-up session. One participant of the AAcue group received the vibrating spider, as she reported to be more afraid for this spider than for the small tarantula; the remaining three participants received the small giant house spider as they were not able to move on to the next step in the fear hierarchy using the small tarantula (ABcue $n=1$; ABnocue $n=2$ ). Of these four participants, three completed the last step with the alternative spider; the remaining participant completed step 9 (ABnocue). The distribution of the spiders used did not differ between the four conditions, $\chi^{2}=2.17, p=.54$.

Repeated measures ANOVAs with time as within-subjects factor (before and after exposure) and group as between-subjects factor (AAcue, AAnocue, ABcue, and ABnocue) were carried out to assess the effectiveness of the exposure therapy. These analyses revealed that the approach distance, FSQ and SBQ scores, and the amount of fear, disgust, and arousal (SUD scores) strongly declined over time, $F \mathrm{~s}>31.33, \mathrm{ps}<.001, \mathrm{p} \eta^{2}>.52$. The analyses yielded no main effects of group, $F s<1$, and no significant time $\times$ group interactions, $F \mathrm{~s}<2.06, p \mathrm{~s}>.12, \mathrm{p} \eta^{2}<.19$.

Table 3

Demographic information and means $(+\mathrm{SD})$ per condition, number of reported spider phobia symptoms according to the SCID-I (maximum 5), number of finished steps of the fear hierarchy with a maximum of 12, ability to touch the spider after the exposure, and total exposure duration in minutes.

\begin{tabular}{lllll}
\hline & AAcue $(n=8)$ & AAnocue $(n=8)$ & ABcue $(n=9)$ & ABnocue $(n=8)$ \\
\hline Age & $21.1(2.59)$ & $21.8(2.82)$ & $21.7(2.00)$ & $21.0(1.77)$ \\
SCID-I & $4.00(.53)$ & $3.88(.99)$ & $4.00(.70)$ & $3.63(.74)$ \\
Steps & $11.25(1.39)$ & $11.00(2.83)$ & $11.89(.33)$ & $11.38(1.77)$ \\
Touch & $n=6$ & $n=7$ & $n=8$ & $n=7$ \\
$\quad \begin{array}{l}\text { spider } \\
\text { Duration }\end{array}$ & $152.38(62.25)$ & $116.38(44.74)$ & $143.44(58.24)$ & $125.38(33.83)$ \\
\hline
\end{tabular}


Table 4

Mean scores $(+\mathrm{SD})$ on the spider-fear related questionnaires before and after exposure, and at follow-up.

\begin{tabular}{|c|c|c|c|c|c|}
\hline Session & Questionnaire & AAcue & AAnocue & ABcue & ABnocue \\
\hline \multirow[t]{3}{*}{ Pre-exposure } & SPQ\#1 & $21.88(2.30)$ & $20.63(4.41)$ & $21.11(3.10)$ & $20.82(3.20)$ \\
\hline & FSQ\#1 & $87.88(14.48)$ & 78.00 (19.37) & $81.56(10.58)$ & $86.88(13.46)$ \\
\hline & SBQ\#1 & 39.80 (12.69) & $32.68(7.29)$ & $36.59(7.93)$ & $39.01(7.81)$ \\
\hline \multirow[t]{2}{*}{ After exposure } & FSQ\#2 & $35.50(16.32)$ & $33.50(27.37)$ & 37.67 (17.83) & $41.13(18.36)$ \\
\hline & SBQ\#2 & $12.08(5.31)$ & $15.95(10.77)$ & $10.56(7.05)$ & $13.29(5.45)$ \\
\hline \multirow[t]{3}{*}{ Follow-up } & $S P Q \# 2^{a}$ & $13.50(4.84)$ & $13.50(5.07)$ & $15.11(4.29)$ & $13.88(5.82)$ \\
\hline & FSQ\#3 & $39.25(17.00)$ & $32.50(25.76)$ & $39.00(14.96)$ & $40.13(21.01)$ \\
\hline & SBQ\#3 & $11.62(7.32)$ & $14.24(11.78)$ & $10.62(70.01)$ & $12.96(7.48)$ \\
\hline
\end{tabular}

Note: $\mathrm{SPQ}=$ spider phobia questionnaire; $\mathrm{FSQ}=$ Fear of Spiders Questionnaire (FSQ); SBQ = Spider Beliefs Questionnaire.

a The SPQ was administered only twice (pre-exposure and follow-up), whereas the FSQ and SBQ were administered three times (pre-, after exposure and follow-up).

Table 5

Subjective Units of Distress, SUD (+SD), and Behavioral Approach Test, BAT (+SD), scores before exposure (\#1), after exposure (\#2), and at follow-up (\#3).

\begin{tabular}{llcccc}
\hline & & AAcue & AAnocue & ABcue & ABnocue \\
\hline SUD\#1 & Fear & $65.29(18.49)$ & $66.25(19.53)$ & $54.78(28.96)$ & $69.88(17.90)$ \\
& Disgust & $68.00(21.28)$ & $86.88(18.33)$ & $86.78(10.56)$ & $86.25(7.54)$ \\
& Arousal & $57.57(17.69)$ & $64.75(28.43)$ & $63.22(30.91)$ & $55.63(22.46)$ \\
& BAT\#1 & $103(61)$ & $140(165)$ & $109(36)$ & $136(61)$ \\
SUD\#2 & Fear & $33.88(21.94)$ & $23.25(21.92)$ & $26.33(17.84)$ & $20.75(17.49)$ \\
& Disgust & $30.50(24.78)$ & $38.25(27.93)$ & $31.00(29.52)$ & $23.75(21.65)$ \\
& Arousal & $22.75(28.05)$ & $31.13(23.55)$ & $29.44(20.65)$ & $20.13(20.17)$ \\
& BAT\#2 & $.25(.46)$ & $2.50(7.07)$ & $.11(.33)$ & $1.25(3.54)$ \\
SUD\#3 & Fear & $37.75(26.54)$ & $33.00(19.99)$ & $46.89(26.70)$ & $42.25(19.70)$ \\
& Disgust & $41.38(19.59)$ & $48.50(32.01)$ & $45.78(25.35)$ & $46.88(27.14)$ \\
& Arousal & $33.25(33.35)$ & $35.88(21.98)$ & $56.11(26.26)$ & $46.75(20.23)$ \\
& BAT\#3 & $2.00(3.25)$ & $1.63(3.42)$ & $.33(.50)$ & $.38(.52)$ \\
\hline
\end{tabular}

These data indicate that the exposure session decreased spider fear, disgust, arousal, and beliefs and that the exposure session was equally successful across conditions.

\subsection{Follow-up}

The follow-up data are presented in Table 4 (Questionnaires) and 5 (SUDs and BAT). To assess relapse, follow-up scores were compared to post-exposure scores. Repeated measures ANOVAs were conducted with time as within-subjects factor (after exposure and at follow-up) and context switch (no switch versus switch) and cue (present versus absent) as between-subjects factors. ${ }^{1}$

For the approach distance (BAT), no main or interaction effects were observed, $F \mathrm{~s}<1.90, \mathrm{ps}>.17, \mathrm{p} \eta^{2}<.062$.

Likewise, for the questionnaires, FSQ and SBQ, no main effect of time, cue, context switch, or interaction effects were observed, Fs $<1.07, p s>.31, \mathrm{p} \eta^{2}<.038$.

The analyses of the SUD scores on the BAT\#2 and BAT\#3 revealed a different pattern. The analysis of the fear scores showed a main effect of time, $F(1,29)=20.76, p<.001, \mathrm{p} \eta^{2}=.42$, and time $\times$ context switch interaction, $F(1,29)=5.41, p=.027$, $\mathrm{p} \eta^{2}=.16$. No other effects were observed, $F \mathrm{~s}<1$. The time $\times$ context switch interaction was analyzed further with separate repeated measures ANOVAs for the switch and no switch groups. These tests indicated that fear did not significantly increased over time for the no switch group, $F(1,15)=2.55, p=.13, \mathrm{p} \eta^{2}=.15$, but did increase for the switch group, $F(1,16)=25.61, p<.001, \mathrm{p} \eta^{2}=.62$. This indicates that scores strongly increased in the switch group (mean increase: $21.00, S D=17.11$ ), but not, or to a lesser extend, in the no switch group (mean increase: $6.81, S D=17.06$ ).

For the disgust scores the analysis revealed a main effect of time, $F(1,29)=14.12, p=.001, \mathrm{p} \eta^{2}=.33$, but no other effects, $F \mathrm{~s}<1.15$,

\footnotetext{
${ }^{1}$ Note: incorporating the amount of completed steps at exposure as covariate yielded similar results.
}

ps $>.29, \mathrm{p} \eta^{2}<.039$. This indicates that, regardless of context switch or cue presence, an increase in subjective disgust feelings was observed at follow-up (mean increase: $14.76, S D=22.06$ ).

The results of the arousal analysis resembled those of the fear scores. A main effect of time was observed, $F(1,29)=19.93$, $p<.001, \mathrm{p} \eta^{2}=.41$, and a time $\times$ context switch interaction, $F(1$, $29)=6.14, p=.019, \mathrm{p} \eta^{2}=.18$. No other effects were observed, $F \mathrm{~s}<1$. The interaction was analyzed further in a similar way as the time $\times$ context switch interaction of the fear scores. These analyses revealed no significant increase in the no switch group, $F(1$, $15)=2.21, p=.16, \mathrm{p} \eta^{2}=.13$, and a significant increase in arousal scores in the switch group, $F(1,16)=24.52, p<.001, \mathrm{p} \eta^{2}=.61$. These results indicate that a switch in context resulted in a stronger increase in arousal $(M=26.65, S D=22.19)$ than no switch $(M=7.63, S D=20.53)$.

Finally, the SPQ score assessed after BAT\#3 was compared to the screening SPQ score. We used the screening SPQ scores as this questionnaire was not administered after exposure but only before treatment. This repeated measures ANOVA revealed a general decrease in scores, $F(1,29)=65.12, p<.001, \mathrm{p} \eta^{2}=.69$, but no other main or interaction effects, $F s<1.23, p s>.27, \mathrm{p} \eta^{2}<.042$.

\subsection{Amount of relapse}

To examine the amount of relapse, the SUD scores before exposure were compared to follow-up scores. Repeated measures ANOVAs indicated that none of the SUD measures returned to their initial level at BAT\#1, Fs $>9.66, p s<.005, \mathrm{p} \eta^{2}>.25$. The mean amount of decrease for fear, disgust, and arousal were, respectively, 22.97 ( $S D=28.14), 37.13$ ( $S D=26.17)$, and $15.81(S D=29.36)$. Looking at the individual data at follow-up, 23 out of 33 participants $(70 \%)$ scored below the cut-off of the SPQ. Of the 10 participants scoring above this cut-off, 8 were able to touch the spider with a glove or brush and 2 were able to touch the spider with their bare finger.

The post experimental questionnaire revealed that 12 persons encountered a spider at home (AAcue: $n=4$, AAnocue: $n=1$, ABcue: $n=3$, ABnocue: $n=4$ ). Eleven out of 17 persons of the cue groups (AAcue and ABcue) were reminded of the exposure session by the bracelet at home. However, only 2 persons of the cue groups (both ABcue condition) reported that the bracelet helped them to retrieve the exposure memory at follow-up. The remaining 15 participants did not report this reminder effect. All participants wore the cue at least $80 \%$ of the time.

\section{Discussion}

The present study examined the role of the exposure context and a cue stemming from this context in spider-fearful persons. The results of our study partly concord with previous studies on context-dependent renewal and attenuation of renewal by a 
retrieval cue. Like in previous (sub)clinical studies using spiderfearful participants, a change in context after exposure resulted in renewed responding (Mineka et al., 1999; Mystkowski et al., 2002, 2003; Rodriguez et al., 1999). This context-dependent renewal was mainly observed in subjective distress measures, more cognitive measures (i.e. FSQ and SBQ), and approach distance to the spider were not affected by a context switch. Unfortunately, unlike other studies (e.g., Dibbets et al., 2008; Dibbets \& Maes, 2011) did the retrieval cue not attenuate renewal. Of course the absence of a retrieval cue effect was not what we aimed at, but this lack of an effect is in line with the results of Culver et al. (2011). Below we will give several potential explanations for the failure to attenuate the renewal effect.

The abovementioned studies, in which a retrieval cue did attenuate fear renewal, used computerized tasks (Dibbets et al., 2008; Dibbets \& Maes, 2011). In these tasks an anticipatory fear response was evoked by linking an initially neutral stimulus to an aversive stimulus. Such a fear response is hardly comparable to fear elicited by spiders (present study) or public speaking (Culver et al., 2011). It is well thinkable that a retrieval cue can indeed attenuate renewal of a mild, experimentally-induced, fear response, but simply does not have the power to attenuate renewal of a strong (sub)clinical fear response.

In the present study only 33 participants were tested, resulting in 8 or 9 persons per condition. This small sample size might have obscured possible retrieval cue effects due to a lack of power. Though this might be true, one can wonder what the clinical value of such retrieval cue is if it cannot be detected in a group of 9 persons (or 17 in case of a two factor analyses, combining AAcue and ABcue). Ideally, a retrieval cue should be effective for all participants, regardless of sample size. Nonetheless, the results might be different in a larger or different sample.

Furthermore, it is known that high-anxious individuals have an increased attentional bias toward threat-related stimuli (see for a meta-analysis Bar-Haim, Lamy, Pergamin, Bakermans-Kranenburg, \& van Ijzendoorn, 2007; Lipp \& Derakshan, 2005). This increased attention may leave less resource for other, co-present stimuli. A novel context, with many salient features, will in that case compete for attention with the familiar, less salient, bracelet (Mackintosh, 1975). The net result of such competition would be retrieval of the fear memory rather than the extinction memory. Our observations are in line with an attentional bias explanation. At followup, the bracelet only reminded two participants of their exposure session, all other participants simply 'forgot' about the cue in the presence of the spider. Including less spider-fearful participants might result in a smaller attentional bias, leaving the opportunity to allocate attention to other, available stimuli. However, the idea of the present study was to eventually implement the retrieval cue in a clinical setting with persons that might display even a higher level of spider fear. A possible solution could be to firstly reduce this bias for threat by attentional training (see for an overview, Mobini \& Grant, 2007). However, several studies indicate that such training is not, or only temporarily, effective in spider-fearful persons (Harris \& Menzies, 1998; Reese, McNally, Najmi, \& Amir, 2010).

Another possibility is that the retrieval cue was simply not salient enough, regardless of attentional resources. Although the bracelet had a distinctive odor and color, it was relatively small and might have been covered by clothing most of the time. During the exposure session several prominent stimuli were surrounding the participant, such as the experimenter, the environment, and exposure-related material. Each of these cues was equally informative, could compete for inhibitory power, and could be linked to the exposure memory (Balsam \& Gallistel, 2009). If the bracelet was simply overshadowed, it would not be salient enough to acquire the preferred retrieval capacity. Presenting the bracelet outside the exposure context would, therefore, not result in the retrieval of the exposure memory. Perhaps more explicit instructions before onset of the exposure could solve this problem, or using a more salient, exposure-related retrieval cue, such as a reminder card with a photo of the participant touching the spider. However, we deliberately choose this bracelet: it can be worn outside the exposure context, continuously remind the participants of the exposure session, and has next to a visual component, a strong citrus odor.

Furthermore, the initial cover-up story about the bracelet might have worked against our aim to let the bracelet function as a retrieval cue. The first-established association between the bracelet and mosquitoes could have reduced the ability of the bracelet to act as retrieval cue after the exposure session. Additionally, if a retrieval cue would be implemented in a clinical exposure session, the therapist would explicitly inform the participant about the function of the retrieval cue before onset of the session. Therefore, for future research we strongly recommend omitting the bogus information and directly inform the participants about the function of the cue.

The current study revealed a discrepancy between the several relapse measures. The participants did demonstrate an (overall) increase in subjective feelings of fear, disgust, and arousal from after exposure to follow-up, but did not reveal any return in negative spider beliefs or fears and on a behavior level they were still able to approach the spider. It is well-thinkable that participants cognitively 'know' that spiders are not dangerous and that they can overcome their behavioral tendency to avoid spiders, but that their subjective feelings and bodily responses do not concord with this notion (see for example, Hugdahl, 1981). To test this assumption we would recommend including autonomic measures, such as skin conductance response and heart rate, in future studies.

A last point that deserves attention is the efficacy of exposure. Though several studies do report a relapse, it is well-thinkable that spider exposure is simply effective enough and that relapse prevention is, at least in the short term, redundant. To test the persistence of exposure therapy we would recommend, for future studies, to add a second follow-up session to assess long-term effects.

In sum, the present study provided evidence for a return in fear and arousal elicited by a change in context after exposure. This context-dependent renewal was mainly observed in subjective feelings; not reflected in more cognitive and approach measures. The retrieval cue did not attenuate this renewal. For future research we would recommend providing additional instructions about the cue before onset of the exposure session, incorporate autonomic measures, and to add a second, long-term, follow-up session. Although the results do not concord with our expectations, the clinical potential of attenuation of renewal is high, and studies such as the present one may help to further develop procedures that are beneficial in a clinical setting.

\section{Conflict of interest}

The authors declare that there are no conflicts of interest.

\section{References}

Abramowitz, J. S. (1996). Variants of exposure and response prevention in the treatment of obsessive-compulsive disorder: a meta-analysis. Behavior Therapy 27, 583-600.

Arntz, A., Lavy, E., Van den Berg, G., \& Van Rijsoort, S. (1993). Negative beliefs of spider phobics: a psychometric evaluation of the Spider Phobia Beliefs Questionnaire. Advances in Behaviour Research and Therapy, 15, 257-277.

Balsam, P. D., \& Gallistel, C. R. (2009). Temporal maps and informativeness in associative learning. Trends in Neurosciences, 32, 73-78.

Bar-Haim, Y., Lamy, D., Pergamin, L., Bakermans-Kranenburg, M. J., \& van Ijzendoorn, M. H. (2007). Threat-related attentional bias in anxious and nonanxious individuals: a meta-analytic study. Psychological Bulletin, 133, 1-24.

Barlow, D. H., Allen, L. B., \& Basden, S. L. (2007). Psychological treatments for panic disorders, phobias, and generalized anxiety disorder. In P. E. Nathan, \& 
J. M. Gorman (Eds.), A guide to treatments that work (3rd ed.). (pp. 351-394) New York: Oxford University Press.

Bouton, M. E. (2002). Context, ambiguity, and unlearning: sources of relapse after behavioral extinction. Biological Psychiatry, 52, 976-986.

Bouton, M. E. (2004). Context and behavioral processes in extinction. Learning and Memory, 11, 485-494.

Brooks, D. C., \& Bouton, M. E. (1993). A retrieval cue for extinction attenuates spontaneous recovery. Journal of Experimental Psychology: Animal Behavior Processes, 19, 77-89.

Brooks, D. C., \& Bouton, M. E. (1994). A retrieval cue for extinction attenuates response recovery (renewal) caused by a return to the conditioning context Journal of Experimental Psychology: Animal Behavior Processes, 20, 366-379.

Choy, Y., Fyer, A. J., \& Lipsitz, J. D. (2007). Treatment of specific phobia in adults. Clinical Psychology Review, 27, 266-286.

Culver, N. C., Stoyanova, M., \& Craske, M. G. (2011). Clinical relevance of retrieval cues for attenuating context renewal of fear. Journal of Anxiety Disorders, 25, 284-292.

Dibbets, P., Havermans, R., \& Arntz, A. (2008). All we need is a cue to remember: the effect of an extinction cue on renewal. Behaviour Research and Therapy, 46, 1070-1077.

Dibbets, P., \& Maes, J. H. R. (2011). The effect of an extinction cue on ABA-renewal: does valence matter? Learning and Motivation, 42, 133-144.

Foa, E. B., Rothbaum, B. O., \& Furr, J. M. (2003). Augmenting exposure therapy with other CBT procedures. Psychiatric Annals, 33, 47-53.

Harris, L. M., \& Menzies, R. G. (1998). Changing attentional bias: can it effect selfreported anxiety? Anxiety, Stress \& Coping, 11, 167.

Havermans, R. C., \& Jansen, A. T. M. (2003). Increasing the efficacy of cue exposure treatment in preventing relapse of addictive behavior. Addictive Behaviors, 28, 989-994.

Hugdahl, K. (1981). The three-systems-model of fear and emotion-A critical examination. Behaviour Research and Therapy, 19, 75-83.

Klorman, R., Weerts, T. C., Hastings, J. E., Melamed, B. G., \& Lang, P.J. (1974). Psychometric description of some specific fear questionnaires. Behavior Therapy, 5, 401-409.

Lipp, O. V., \& Derakshan, N. (2005). Attentional bias to pictures of fear-relevant animals in a dot probe task. Emotion, 5, 365-369.

Mackintosh, N. J. (1975). A theory of attention: variations in the associability of stimuli with reinforcement. Psychological Review, 82, 276-298.

Marks, I. M., Hodgson, R., \& Rachman, S. (1975). Treatment of chronic obsessivecompulsive neurosis by in-vivo exposure: a two-year follow-up and issues in treatment. British Journal of Psychiatry, 127, 349-364.

Martin, C. S., Pollock, N. K., Bukstein, O. G., \& Lynch, K. G. (2000). Inter-rater reliability of the SCID alcohol and substance use disorders section among adolescents. Drug and Alcohol Dependence, 59, 173-176.
Mineka, S., Mystkowski, J. L., Hladek, D., \& Rodriguez, B. I. (1999). The effects of changing contexts on return of fear following exposure therapy for spider fear. Journal of Consulting and Clinical Psychology, 67, 599-604.

Mobini, S., \& Grant, A. (2007). Clinical implications of attentional bias in anxiety disorders: an integrative literature review. Psychotherapy: Theory, Research, Practice, Training, 44, 450-462.

Muris, P., \& Merckelbach, H. (1996). A comparison of two spider fear questionnaires. Journal of Behavior Therapy and Experimental Psychiatry, 27, 241-244.

Mystkowski, J. L., Craske, M. G., \& Echiverri, A. M. (2002). Treatment context and return of fear in spider phobia. Behavior Therapy, 33(3), 399-416.

Mystkowski, J. L., Craske, M. G., Echiverri, A. M., \& Labus, J. S. (2006). Mental reinstatement of context and return of fear in spider-fearful participants. Behavior Therapy, 37, 49-60.

Mystkowski, J. L., Mineka, S., Vernon, L. L., \& Zinbarg, R. E. (2003). Changes in caffeine states enhance return of fear in spider phobia. Journal of Consulting and Clinical Psychology, 71, 243-250.

Neumann, D. L., \& Kitlertsirivatana, E. (2010). Exposure to a novel context after extinction causes a renewal of extinguished conditioned responses: Implications for the treatment of fear. Behaviour Research and Therapy, 48, 565-570.

Neumann, D. L., \& Longbottom, P. L. (2008). The renewal of extinguished conditioned fear with fear-relevant and fear-irrelevant stimuli by a context change after extinction. Behaviour Research and Therapy, 46, 188-206.

Öst, L. G. (1997). Rapid treatment of specific phobias. In G. C. L. Davey (Ed.), Phobias: A handbook of theory, research and treatment (pp. 227-246). Chichester, England: John Wiley \& Sons.

Reese, H. E., McNally, R. J., Najmi, S., \& Amir, N. (2010). Attention training for reducing spider fear in spider-fearful individuals. Journal of Anxiety Disorders, 24, 657-662.

Rodriguez, B. I., Craske, M. G., Mineka, S., \& Hladek, D. (1999). Context-specificity of relapse: effects of therapist and environmental context on return of fear. Behaviour Research and Therapy, 37, 845-862.

Szymanski, J., \& O'Donohue, W. (1995). Fear of spiders questionnaire. Journal of Behavior Therapy and Experimental Psychiatry, 26, 31-34.

Van Groenestijn, M. A. C., Akkerhuis, G. W., Kupka, R. W., Schneider, N., \& Nolen, W. A. (1997). Gestructureerd Klinisch Interview voor de vaststelling van DSM-IV as I stoornissen Vertaling van Structured clinical interview for DSM-IV axis I disorders SCID-I/P version 2.0 (First M.B., Spitzer R.L., Gibbon M., Williams J.B.W., 1996, 1997). Lisse: Swts \& Zeitlinger/Hardcourt Publishers.

Vansteenwegen, D., Vervliet, B., Hermans, D., Beckers, T., Baeyens, F., \& Eelen, P. (2006). Stronger renewal in human fear conditioning when tested with an acquisition retrieval cue than with an extinction retrieval cue. Behaviour Research and Therapy, 44, 1717-1725. 